\title{
The Physical and Clinical Aspects of Radiation Therapy in Skin Cancer and Subcutaneous Tissue Neoplasm
}

\author{
Marzena Janiszewska ${ }^{1}$, Maciej Raczkowski ${ }^{1}$, Jacek Walczak1 ${ }^{1}$, Krzysztof Składowski², \\ Adam Maciejczyk ${ }^{3}$ \\ ${ }^{1}$ Medical Physics Department, Lower Silesian Oncology Center, Wroclaw, Poland \\ ${ }^{2} 1^{\text {st }}$ Radiation Oncology Clinic, Institute of Oncology-Maria Sklodowska-Curie Memorial Cancer Center, Branch in Gliwice, \\ Gliwice, Poland \\ ${ }^{3}$ Department of Radiotherapy, Lower Silesian Oncology Center, Wroclaw, Poland \\ Email: *janiszewska.m@dco.com.pl, raczkowski.m@dco.com.pl,walczak.j@dco.com.pl, skladowski@io.gliwice.pl, \\ adam.maciejczyk@dco.com.pl
}

How to cite this paper: Janiszewska, M., Raczkowski, M., Walczak, J., Składowski, K. and Maciejczyk, A. (2018) The Physical and Clinical Aspects of Radiation Therapy in Skin Cancer and Subcutaneous Tissue Neoplasm Health, 10, 730-748.

https://doi.org/10.4236/health.2018.106056

Received: June 1, 2018

Accepted: June 4, 2018

Published: June 7, 2018

Copyright (C) 2018 by authors and Scientific Research Publishing Inc. This work is licensed under the Creative Commons Attribution International License (CC BY 4.0).

http://creativecommons.org/licenses/by/4.0/

\begin{abstract}
Cancers, malignant melanoma and sarcomas of the skin represent the most common group of malignancies in humans. The main treatment method of almost all skin cancers and subcutaneous tissue tumours is surgery, which consists of complete removal of a neoplastic lesion, with an adequate margin of healthy tissue. Radiotherapy plays an adjuvant role in this process, meaning complementing of the surgical procedure. This study compared four methods of irradiation treatment of cancer located in the skin or in subcutaneous tissues: contact brachytherapy, conventional orthovoltage therapy, electron beam conformal teleradiotherapy and IMRT dynamically shaped photonic beams conformal teleradiotherapy. In order to compare the methods and techniques of surface radiotherapy, following specific objectives were formulated. At the beginning in order to compare the scopes of the absorbed doses at different tissue depths, an analysis of parameters describing particular beams or radiation source has been performed-the curves for the absorbed-dose depth drop-offs. Doses distribution in tissue-like phantoms stimulating homogeneous cuboidal tissue block has been determined. A quality comparison of dose distribution in $2 \mathrm{D}$ and $3 \mathrm{D}$ treatment planning system for contact brachytherapy application has been made. The dose distribution for electron beam in the system has been determined. Conformal plannings for electron beam treatment, contact brachytherapy applicator treatment and 4 photon beams treatment optimized in IMRT technology have been performed. Dose distribution has been performed for the irradiated female patient within the well chest-the target included the recurrence area in the
\end{abstract}


post-operative scar. The radiation therapy with X-rays has actually been completely eliminated from skin cancer and subcutaneous tissue radiotherapy by the electrons generated in linear accelerators, contact brachytherapy HDR and by high-energy photons used in conformal techniques, ex. IMRT. It is because the residual dose beyond the target is the highest for single X-ray beam. Although in brachytherapy HDR a rapid dose drop-off is observed, $5 \mathrm{~cm}$ from its normalization level for the target the residual radiation remains at the level of several percent. So, both X-rays beam radiation and brachytherapy in skin cancer treatment is connected with the administration of the dose with a high gradient in the health tissues. The dose distribution for photon conformal techniques IMRT or for electron radiation looks different. There with the dose normalization at the level of $90 \%$ or $85 \%$ we deal with the dose layer, the division does not exceed $15 \%$ of heterogeneity.

\section{Keywords}

Radiation Therapy, Skin Cancer, Subcutaneous Tissue Neoplasm, The Physical Aspects of Radiation Therapy, The Clinical Aspects of Radiation Therapy

\section{Introduction}

\subsection{Radiotherapy of Skin Cancer and Subcutaneous Tissue Cancer}

Cancers, malignant melanoma and sarcomas of the skin represent the most common group of malignancies in humans. According to their location, all skin lesions are relatively easy to diagnose both medically and oncologically. Their diagnosis is based on microscopical examination of the tissue material obtained surgically from margin of a large lesion (incisional biopsy), or from entire removed small skin lesion via excision biopsy [1].

The main treatment method of almost all skin cancers and subcutaneous tissue tumours is surgery, which consists of complete removal of a neoplastic lesion, with an adequate margin of healthy tissue. Radiotherapy plays an adjuvant role in this process, meaning complementing of the surgical procedure. It may also be a therapeutic alternative, especially in situations, in which patient does not agree surgery, or tumor excision will be associated with bad cosmesis, disfigurement, injury or handicap [2].

Radiotherapy, plays an important role in management of many neoplasms, including soft tissue integument tumors and skin cancers. From the beginning of its, "birth", that is, from the end of the XIX-th century, radiotherapy was an alternative to surgery. It was due to the fact that the first radiotherapeutic instruments were producing "soft" X-rays, for which, maximum dose was located on the skin surface. In contrast, soft tissue tumors of the integumentary system, for many years were considered as radiation-resistant neoplasms, until research of the 70. and 80. of the last century, when post-operative irradiation has been giving radiotherapy, its, "official status" in clinical practice [3]. 
The aim of the project is to compare four methods of irradiation treatment of cancer located in the skin or in subcutaneous tissues: contact brachytherapy, conventional orthovoltage therapy, electron beam conformal teleradiotherapy and IMRT-dynamically shaped photonic beams conformal teleradiotherapy.

\subsection{Radiotherapy of Skin Neoplasms}

Surgery is a basic method of treatment of patients with skin cancer. It is aimed at a total resection of the tumor/neoplastic infiltration, with a wide margin of the healthy skin adjacent to the infiltrate circumferentially and subcutaneous tissue underlying at the bottom [4]. Radiotherapy may be an alternative to surgery only in some selected sites (e.g.: head) and in so called early stages of advancement (I and II) of the Squamous Cell Carcinoma (SCC) or Basal Cell Carcinoma (BCC). It may also be used as an adjuvant post-operative treatment, in cases of late stages of advancement (III-IV) of those cancers. In treatment of Malignant Melanoma ( $M M)$, radiotherapy is mostly used as a post-operative therapy in cases with metastases to lymph nodes and those with high risk of local recurrence. It is also utilized as an attempt of radical treatment in some rare cases of inoperable melanoma of the mucosae of oral or nasal cavity, sinuses, and vagina.

\subsection{Indications for Radiotherapy (as the Main Treatment Procedure)}

1) SCC and BCC localized on the face (palpebrae, nose, lips, and external acoustic meatus).

2) SCC and BCC-localized elsewhere, tumor advancement-stages T1-2, and in cases of lack of the informed consent to surgical procedure.

\subsection{Indications for Adjuvant Radiotherapy}

1) Non-radical surgical procedure for SCC and BCC (microscopically positive or doubtful margin of the healthy tissue, meaning $<10 \mathrm{~mm}$ ),

2) Extra-capsular infiltration due to metastases of SCC to the lymph nodes,

3) Peri-neural infiltrates of the SCC and BCC,

4) Clinical stage IIB and III of malignant melanoma.

Superficial spreading of the primary skin cancer makes irradiation procedure simple. The therapeutic dose is focused on the skin or infiltrate surface, without penetration inside the adjacent, healthy tissues. These requirements are almost ideally met by radiotherapy via one field electron technique. Target field is designed mainly according to clinical examination, and in particular, localization, size and depth of the neoplastic infiltrate. Imaging studies, including a computerized tomography are considered helpful, since they allow to conformalization the conducted treatment, via precisely designed target volume and localization of organs at risk (OARs), or provide the possibility of combining external beams and contact brachytherapy [5].

For SCC patients the irradiation of regional lymph nodes should be considered. In radical treatment of the primary skin cancer, in addition to the elec- 
tron beam and ortovoltage X-ray, the contact (surface) brachytherapy HDR can be applied. A magnitude of the treatment dose depends directly on size of the tumour lesion, and oscilates in the following ranges:

1) from $45 \mathrm{~Gy}$, administered in 9 - 15 fractionated doses over 21 days, to 60 Gy administered in 30 fractionated doses, over 6 weeks, for electron or mixed type of irradiation;

2) from 18 - $22 \mathrm{~Gy}$, in a single dose, to 40 - $45 \mathrm{~Gy}$, administered in $10-12$ fractionated doses, over 2-2, 5 weeks;

3) from $42 \mathrm{~Gy}$, administered in 14 fractionated doses, over 3 weeks, to $80 \mathrm{~Gy}$, administered in 45 fractionated doses, over 8 weeks.

Radiotherapy outcome of the skin cancer patient is based on observation and evaluation of the remission of neoplasm during irradiation. The observation of an acute post-radiation skin reaction, which should achieve a phase of confluent epidermal exfoliation "in wet" (stage III) in 4 - 5 week of the irradiation, is crucial. A total remission of the cancer, after completion of the therapy is related to a good outcome.

A situation is different, when a locally or regionally advanced skin cancer infiltrates some deeply localized structures (e.g.: fascia, muscle or bone) and was previously surgically removed, in a non-radical manner. In such a case, radiotherapy planning should be based on modern systems of three-dimensional visualization of the dose distribution that is derived from a few beams of the megavoltage photon irradiation. Here also, similarly to a definitive radiotherapy of skin cancer, X-ray irradiation and contact brachytherapy are being used.

\subsection{Radiotherapy of the Subcutaneous Tissue Tumors}

Until about 20 years ago, surgical excision of a tumor was the most common surgical procedure, related to patients with malignancies of the subcutaneous tissue (soft tissue sarcomas, adenocarcinomas of the skin and its accessory organs). However, in many cases, this kind of therapy was insufficient, since a local recurrence was taking place, and subsequently, many of those patients were dying due to metastases in distant organs. These clinical experiences created a change of the therapeutic approach, in the way that the surgical procedures were followed by post-operative radiotherapy. High efficacy of such a combined treatment (percentage of the local control was about $80 \%$ - 90\%) has already been, for a long time, confirmed by evidence-based oncology data.

Until recently, radiotherapy was considered as a standard adjuvant treatment, after surgery, in all patients with tumors with high and intermediate grade of histological malignancy (grading-G), and with advanced stage of primary tumor. However, small tumors (with diameter $\leq 5 \mathrm{~cm}$ ), especially the ones located above fascias, rarely relapsed after excision, what suggested that in such cases, the adjuvant radiotherapy might not be needed. Today, the main indication for the post-operative radiotherapy is lack of the radical surgery effects, revealed by pathomorphological (microscopical) examination of the excised tissue margin. A so called post-operative tumour bed, with sufficient margin of the adjacent, 
healthy tissue is exposed to irradiation. A standard size of the margin is $5-7 \mathrm{~cm}$; however, many oncology centers have used wider margin when tumors had a diameter larger than $15 \mathrm{~cm}$.

\subsection{Post-Operative Irradiation}

Post-operative irradiation is planned, according to the grade of malignancy of the tumor, surgical margin, and experience of oncology center.

Independently of these factors, an irradiation field must cover the whole area of surgical scar, and the sites of the drainage of the tumor bed, in such a way, that the superficial layers of skin receive almost full dose of irradiation. Placement of metal clips in the surgical bed helps in its specification on CT scans in computer treatment planning. At the present time, the technique of conformal radiotherapy has commonly been used. It involves close and individual adjustment of geometry of the irradiation dose to the shape and size of the tumor post-operative bed-e.g.: Intensity-Modulated Radiotherapy (IMRT). It allows to avoid a risk of post-irradiation complications, what has a particular importance for the treatment of neoplasms, located either outside of the limbs or on them, in close proximity to the X-ray sensitive joints.

For the post-operative treatment, doses in the range of $60-70 \mathrm{~Gy}$, are usually being administered over 6 - 7 weeks.

\subsection{Radiotherapy Might Also Be Used before Surgical Procedures}

A few advantages of this approach can be outlined. Firstly, it is possible, prior to the treatment, when a tumor is still intact, and interdisciplinary evaluation of the disease is done by a team consisting radiotherapists, clinical oncologists, and surgeons who accept the therapeutic plan. In addition, this management possibly assures that the radiotherapy will not be delayed, or should not be rejected, due to possible surgical complications. Secondly, prior to surgery, it is possible to use smaller irradiation doses, when the regions surrounding tumor are intact, an tumor adjacent tissues are better oxygenated. Thirdly, a volume of irradiation and number of joints involved to the target volume might be smaller, in comparison to a post-operative situation, and in this way, functional capacity of the limb can be improved. Finally, the proponents of the pre-operative radiotherapy believe that this method of irradiation, by causing shrinking of the tumor mass, can facilitate the subsequent surgical treatment [6]. In contrast, the opponents of this approach, emphasize the difficulties in assessment of a margin of the lesion that was previously irradiated, and can contribute to the increased risk of surgical complications; they also address the issue of lack of sufficient histopathological data, which generally are being provided in a post-operative report, related to the excised tumor. In majority of oncology centers, a standard pre-operative irradiation dose has been established as $50 \mathrm{~Gy}$, administered in 25 fractionated doses, over 5 weeks.

The other method of radiotherapy in patients with soft tissue tumors is HDR brachytherapy. The main advantage of brachytherapy, consisting of a placement 
in tumor bed numerous catheters, so called applicators, releasing an izotope, e.g.: iryd-192, is shorter treatment time, equal to $4-6$ days. This represents a significant difference in comparison to a few weeks, required for classical schemes of fractionated teletherapy. It is considered that in case of brachytherapy, dispersion of the irradiation dose to the anatomically important regions (joints or reproductive organs) is also smaller, and may potentially lead to their protection and preservation of function. Analysis of costs of the brachytherapy and classical radiotherapy revealed also that the adjuvant brachytherapy, used in treatment of soft tissues sarcomas of the integument is less expensive than the radiotherapy of external beams [7].

Brachytherapy can also be used in patients with recurrence after previous teletherapy. The main disadvantage of brachytherapy is the fact that it prolongs hospitalization, and necessitates immobilization of the patient during the treatment.

\section{Materials and Methods}

The aim of the project is to compare four methods of irradiation treatment of cancer located in the skin or in subcutaneous tissues:

1) contact brachytherapy,

2) conventional orthovoltage therapy,

3) electron beam conformal teleradiotherapy,

4) IMRT dynamically shaped photonic beams conformal teleradiotherapy.

\section{Surface Radiotherapy Physics}

In order to compare the techniques and methods of surface radiotherapy the following specific objectives have been formulated:

1) In order to compare the scopes of the absorbed doses at different tissue depths, an analysis of parameters describing particular beams or radiation source has been performed-the curves for the absorbed-dose depth drop-offs.

2) Doses distribution in tissue-like phantoms stimulating homogeneous cuboidal tissue block has been determined. A quality comparison of dose distribution in 2D and 3D treatment planning system for contact brachytherapy application has been made. The dose distribution for electron beam in the system has been determined.

3) Conformal plannings for electron beam treatment, contact brachytherapy applicator treatment and 4 photon beams treatment optimized in IMRT technology have been performed. Dose distribution has been performed for the irradiated female patient within the well chest-the target included the recurrence area in the post-operative scar. The obtained dose distributions have been compared by means of quality methods.

4) Summing up of physical doses from conformal treatment plannings has been performed: 1st stage: conformal planning for external beam radiation of the rib cage area after mastectomy $+2^{\text {nd }}$ stage-additional radiation of subcutaneous tissues within the scar area. The $2^{\text {nd }}$ stage has been planned by means of contact 
brachytherapy technology, alternatively by means of electron beam radiation.

\section{Results}

The dose distribution is the essential physical parameter describing the effect that the radiation beam triggers in biological material. It is calculated within the central axis of beam, by moving the radiation beam detector deep into the tissue-like material. Because of water properties of radiation absorption that are very similar to soft tissue, the doses are determined in water phantoms. The relation between the dose and the depth (of tissue) is called a percentage deep-dose (PDD). This relation can be presented in a tabular or graphical form. Figure 1 compares the percentage deep-doses of the axis of the beam for two energies of electron beams of 6 and $9 \mathrm{MeV}$, of conventional radiation beam and of two beams of photons generated in the linear accelerator with energies of 6 and 10 $\mathrm{MeV}$. The corpuscular character of electron radiation and its basis characteristics-direct ionization of biological material-determines the sudden dose drop-off at the depth of merely several centimetres. Photonic beams that after entering the biological environment ionize it indirectly are much more piercing and the dose volume at the determined depth becomes greater as the beam energy increases.

Figure 1 shows also that contrary to the photons the electrons have limited scope in the centre of radiation. Thanks to that the tissues protection beyond the desired therapeutic depth for the planning target volume is much better during the electron beam treatment than for the photon treatment. The photon beams are used for radiation of cancer located deeper in the patient's body. The exception here is conventional radiation beam with kilovolt energy of $150-250 \mathrm{keV}$. It is less piercing than beams with megavolt energies and it does not include a build-up region. Therefore $100 \%$ of the dose is absorbed in the patient's skin. Table 1 shows deep-dose distribution for typical $150 \mathrm{keV}$ and $225 \mathrm{keV}$ radiation beams with respectively WP $0.6 \mathrm{~mm} \mathrm{Cu}$ and WP $17 \mathrm{~mm} \mathrm{Cu}$ for field $10 \times 10 \mathrm{~cm}$ and for electron beams of 6 and $9 \mathrm{MeV}$. Additionally it shows (last column) the dose drop-off in the depth function for brachytherapy contact (surface) applicator with high dose rate.

\subsection{Electron Beam Therapy}

The sudden drop-off of the percentage deep-dose beyond the therapeutic field is one of the most useful features of electron beam disintegration in clinical use. The initial increase of the dose after it has entered the absorbent results from the increase of electron stream within the major axis of the beam and is related to the electrons scattering effect and the production of secondary electrons. The value of percentage deep-dose on the phantom surface (or patient's skin) is ca. $85 \%$ of its maximum value. The determination of the absolute dose value on the skin is impossible due to the boundary conditions of the junction of two environments: air and patient's body. Therefore the definition of surface must be 


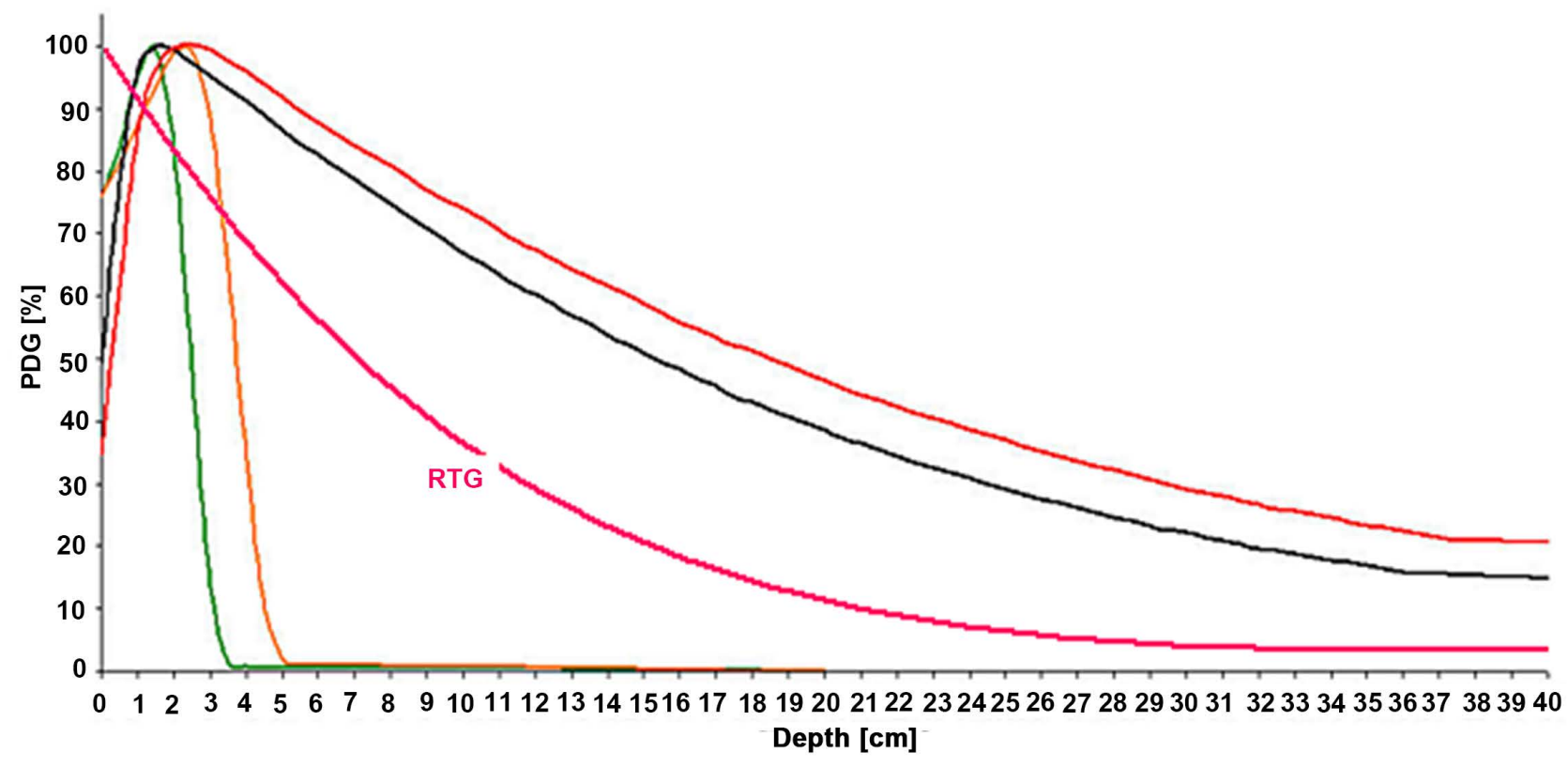

$-6 \mathrm{Mev}-9 \mathrm{Mev}-9 \mathrm{Mev}$ fotony $-10 \mathrm{Mev}$ fotony

Figure 1. Percentage deep-dose for selected energies.

Table 1. Percentage depth dose for analysed beam.

\begin{tabular}{|c|c|c|c|c|c|}
\hline Depth $(\mathrm{cm})$ & $\begin{array}{c}\text { \% Dose } \\
150 \mathrm{keV} \\
\text { WP } 0.6 \mathrm{~mm} \mathrm{Cu}\end{array}$ & $\begin{array}{c}\text { \% Dose } \\
225 \mathrm{keV}, \\
\text { WP } 1.7 \mathrm{~mm} \mathrm{Cu}\end{array}$ & $\begin{array}{c}\% \text { Dose } \\
\text { Electrons } \\
6 \mathrm{MeV}\end{array}$ & $\begin{array}{c}\% \text { Dose } \\
\text { Electrons } \\
9 \mathrm{MeV}\end{array}$ & $\begin{array}{c}\text { \% Dose } \\
\text { FLAP for HDR Ir192 }\end{array}$ \\
\hline 0 & 100 & 100 & 77.3 & 81.3 & 100 \\
\hline 0.5 & 97.8 & 98.3 & 86.8 & 86.3 & 83.3 \\
\hline 1 & 94.9 & 95.3 & 97.5 & 91.9 & 63 \\
\hline 1.2 & --- & --- & 100 & 94.2 & --- \\
\hline 1.5 & --- & --- & 98.7 & 96.6 & --- \\
\hline 2 & 86.7 & 87.6 & 75.7 & 100 & 42.6 \\
\hline 2.5 & --- & --- & 39 & 96 & --- \\
\hline 3 & 77.5 & 79 & 7.8 & 81.1 & 30 \\
\hline 3.5 & --- & --- & 0.8 & 54.7 & --- \\
\hline 4 & 68.1 & 70.3 & 0.6 & 25.9 & 22 \\
\hline 5 & 59.6 & 62 & --- & 1.5 & 16.5 \\
\hline 6 & 51.8 & 54.3 & --- & 1.1 & 12.5 \\
\hline
\end{tabular}

related to the depth. This depth starts below the cuticle, at about $0.1-0.15$ $\mathrm{mm}$.

The initial increase of the dose after it has entered the absorbent results from the increase of electron stream within the major axis of the beam and is related to the electrons scattering effect and the production of secondary electrons.

Once the electrons enter the absorbent, they start losing their energy in the subsequent interactions. Initially, they lose about $2 \mathrm{MeV}$ per centimetre of their 
distance in the absorbent. After almost each interaction, the electron changes its direction and as a result it moves angled towards its original direction. That on the other hand is reflected in the distance it made in the absorbent.

The path that the electron travels in the subsequent layers of irradiated environment is different from its path at the beginning of its movement. The deeper the electron penetrates the absorbent, the less energy it has the longer its path becomes due to the subsequent interactions. This leads to the growth of energy deposited in subsequent layers-the dose increases. The effect of the dose increase depends on the electrons' energy. This is connected to the fact, that the scattering strongly depends on the energy-it becomes smaller while the energy grows. Low-energy beam becomes easily scattered, which is visible in the fact that the electron path becomes deviated from the original one while the electron enters the environment. High-energy electrons become less scattered, therefore just after the entering the centre their path remains almost linear. It results in the smaller area of the increase of absorbed electron dose. The area of fast dose drop-off occurring deeper in the absorbent is related to the gradual drop-off of the electron number in the beam due to their slow down. While moving in the environment the electrons lose their energy and their paths get curved towards different directions. The loss of energy is related to ionization, inducing the atoms of the centre and radiation losses that are triggered by the changes in electron movement change and their slow down. As a result of these interactions the scope of the electrons is limited which causes the dose drop-off up to a certain depth, below which the PDD curve is almost the same as depth axis. Within this centre the dose is deposited by the braking radiation generated by braking electrons.

One of the carcinoma radiotherapy rules is that the dose provided to the tumour (target volume) has to be homogeneous. Radiation by means of one electron beam is possible only thanks to the characteristic dose distribution, as shown on Figure 1.

The dose depth at the level of $90 \%\left(R_{90}(\mathrm{~cm})\right)$ beyond the maximum is define as a therapeutic scope for electron beam therapies. $R_{90}$ depth, if possible, should be the same as a therapeutic margin of the radiation area. The therapeutic scope strongly depends on the electron beam energy. Practically, the choice of the dose value within the planning target volume is a compromise between the characteristics of electron division, such as: the build-up region, the curve change beyond the maximum point, the gradient drop-off, the allowed difference in the dose across the target and the requirement of tissue protection attached to radiation area. By introducing the term of dose normalization towards isodose with $90 \%$ value, we need to accept its heterogeneity within the target area, thus the $10 \%$ increase, that is to say to the maximum value.

\subsection{Contact Brachytherapy HDR}

In case of surface (contact) brachytherapy a moving source HDR can be used. The most popular isotope used in this technology is Iridium 192 with half-life of 
74 days and cylinder shape $3 \mathrm{~mm}$ long and with a diameter of $1.3 \mathrm{~mm}$ (so called point source).

In case of brachytherapy the dose drop-off is inversely proportional to the square of the distance. Such a universal dependence enables a precise estimation of the dose distribution from the point source, linear source or from the surface of the applicator used for treatments of skin changes.

In order to cover a surface, radiation field of several square centimetres with a homogeneous dose, one uses a system of parallel guide catherers fixed in tissue-like material. Such a tissue-like applicator is generally known as FLAP. The guide catherers-the channels where a moving source is inserted are situated 1 $\mathrm{cm}$ from each other. The fixed geometry of the applicator allows the prepared treatment planning realisation in a repeatable way.

Because of the very high dose gradient from the very source to the treated area, the part of the suddenly decreasing dose is deposited in an applicator material at the layer of $0.5 \mathrm{~cm}$. The dose is conventionally specified at the distance of $0.5 \mathrm{~cm}$ from the applicator's surface. The impassable distance of dose normalization in brachytherapy counts $1 \mathrm{~cm}$. In case of this treatment method we cannot obtain a homogenous dose in target volume. Similarly to X-beam radiation we deal with dose drop-off in relation to the depth. Therefore this technique, similarly to single-field technique of X-beam, can be specified as gradiental.

In order to complementary compare the radiation technique with the use of electron beam with brachytherapeutic application HDR, doses distributions have been scheduled in a phantom simulating homogeneous cuboidal tissue block. In both cases a $6 \times 6 \mathrm{~cm}$ area has been defined and the dose 6 Gy has been specified on $0.5 \mathrm{~cm}$.

The calculations for brachytherapy application have been performed in 2 systems of treatment planning: in Abacus treatment planning and in 2D Eclipse-Brachy Vision system. The specification of guide catherers arrangement and the dose calculation reflects the actual applicator position, which shape and location is visible on CT scans. Figure 2 shows dose distribution received in system $2 \mathrm{D}$ and 3D. In both systems the same nominal times of radiation of 370 seconds have been reached. The calculations have been made for the system of 7 guide catherers situated $1 \mathrm{~cm}$ from each other. There have been presented doses distributions: in a crosswise surface of the applicator and in the frontal surface at the dose specification depth, i.e. at $0.5 \mathrm{~cm}$. Relying on isodoses distribution we can deduce the deposited dose depth: by the normalization $6 \mathrm{~Gy}$ at the depth of $0.5 \mathrm{~cm}$ under the skin we receive $8 \mathrm{~Gy}$ dose on the skin and $1 \mathrm{~Gy}$ at $4.5 \mathrm{~cm}$ from the applicator's surface. High-dose area beyond referential line is thus substantial. The dose drop-off within the applicator area $(0.5 \mathrm{~cm})$ is $2 \mathrm{~Gy}$ (Figure 3).

This $2 \mathrm{D}$ treatment planning method can be used in case of changes remote from the critical structures and for flat surfaces. When the surface is oval or crosswise (ex. rib cage) CT image data should be collected and an optimization by means of $3 \mathrm{D}$ system should be performed. The reconstruction of crosswise surface with $2 \mathrm{D}$ methods is very time-consuming and it can lead to negligence 

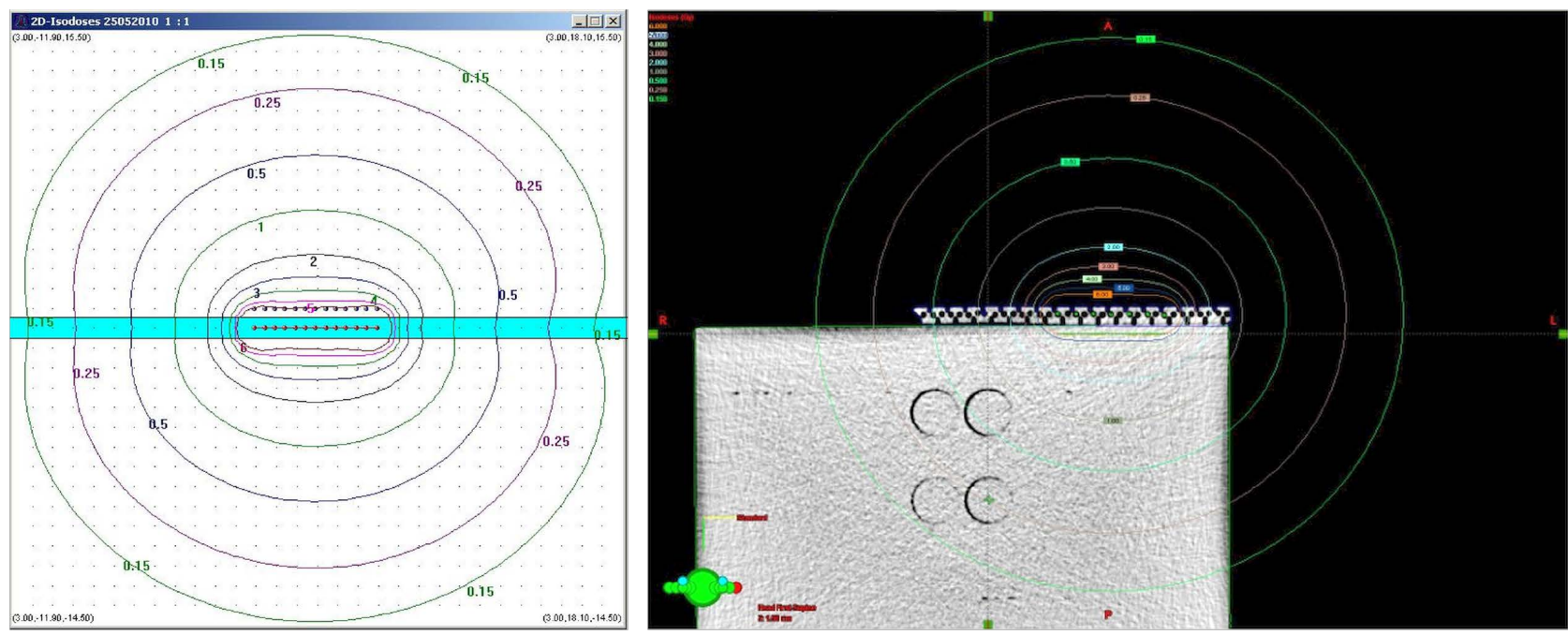

2D

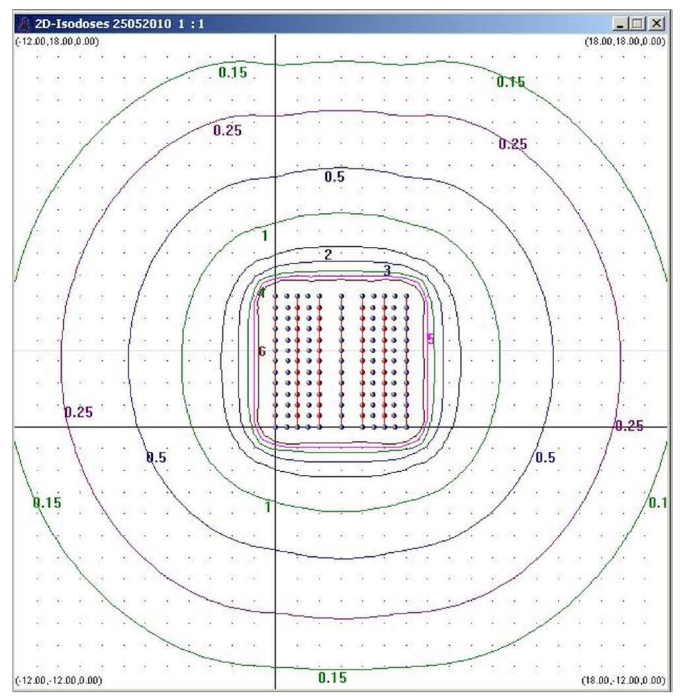

(18:00.12:00,0.00)
3D

(a)

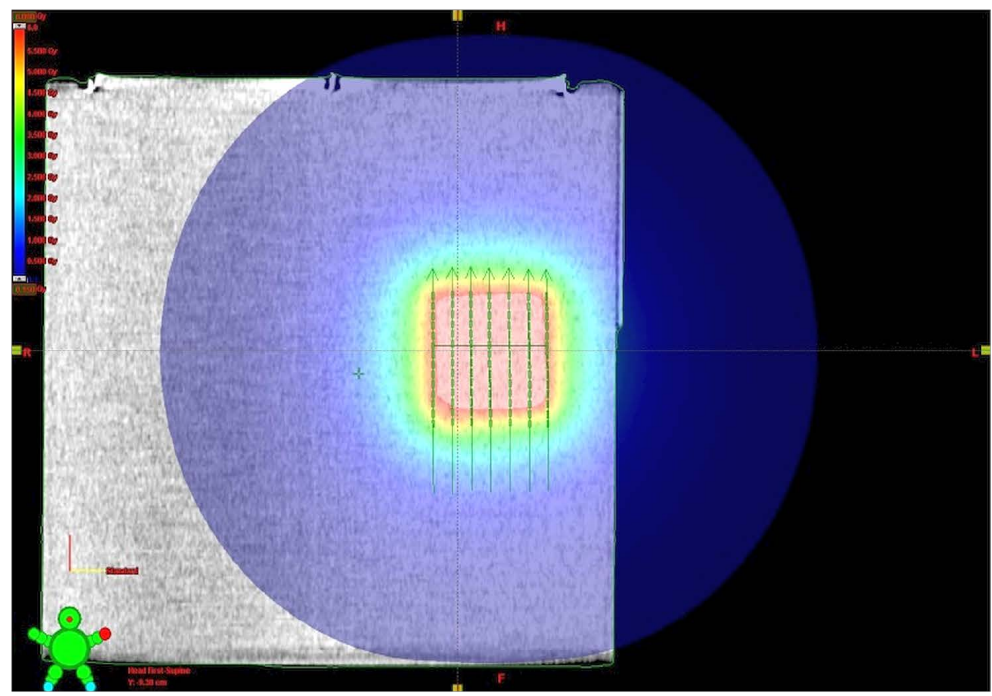

(b)

Figure 2. Doses distribution for FLAP applicator, reached in 2D and 3D systems. (a) Division in crosswise plane; (b) Division in frontal plane.

resulting from the applicator's geometry specification performed by the physicist who plans the treatment.

The doses distribution for electron beam has been performed with the use of treatment planning system Eclipse, by Varian, based on Monte Carlo computational algorithm. Example calculations for $6 \mathrm{Mev}$ beam have been done. The dose distribution has been expressed in percents.

Yellow isoline (100\%) shows the referential dose value after 95\% normalization which in case of standard 2 Gy fractionation determines max. 2.105 Gy dose in the axis of the beam. Depending on the bolus thickness that has been used, one can reach $100 \%$ or $95 \%$ dose on the skin (Figure 4 ). 


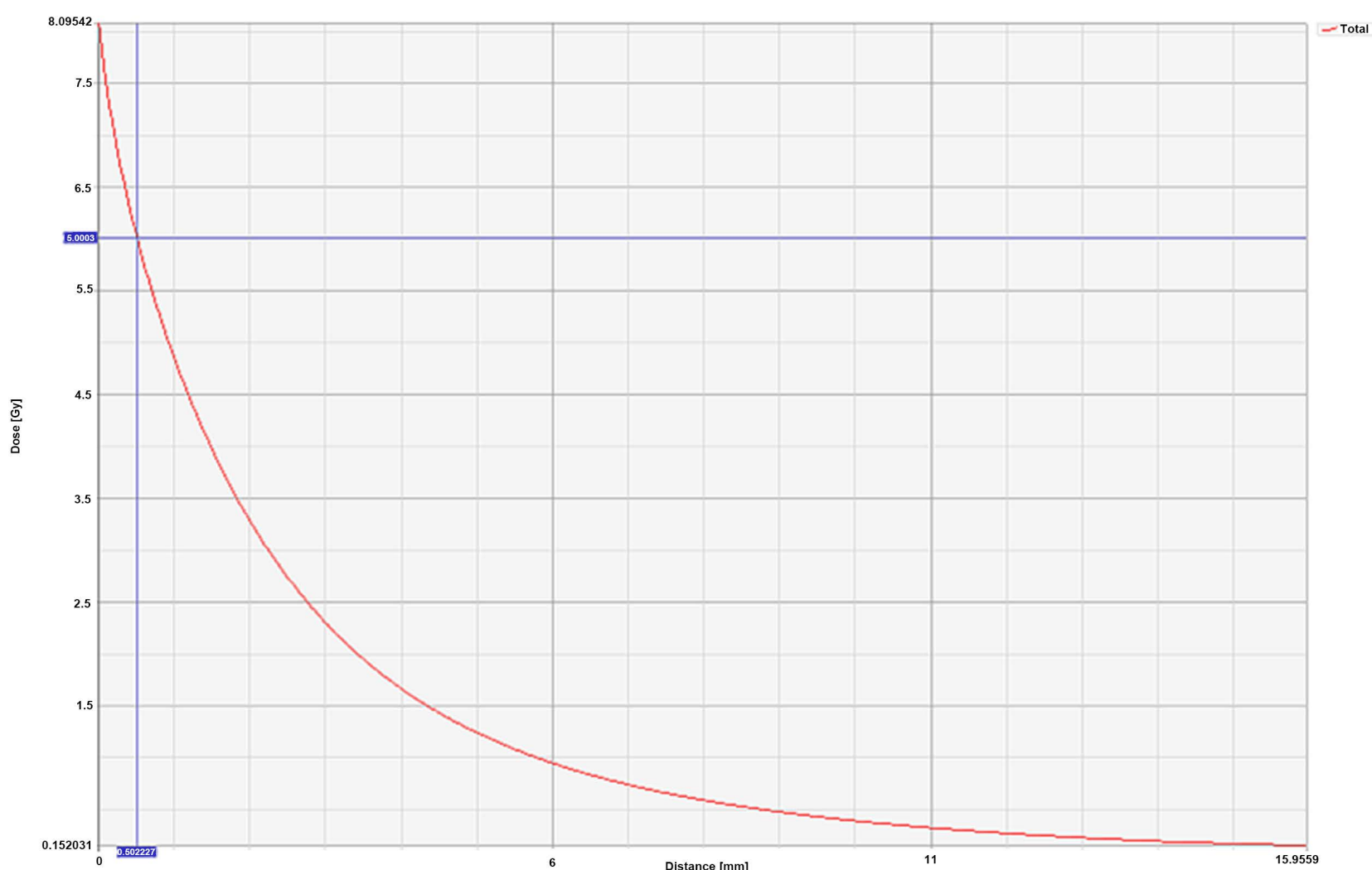

Figure 3. Dose drop-off according to the distance of applicator's surface, deep into the skin. Dose drop-off at the first $0.5 \mathrm{~cm}$ is 2 Gy.

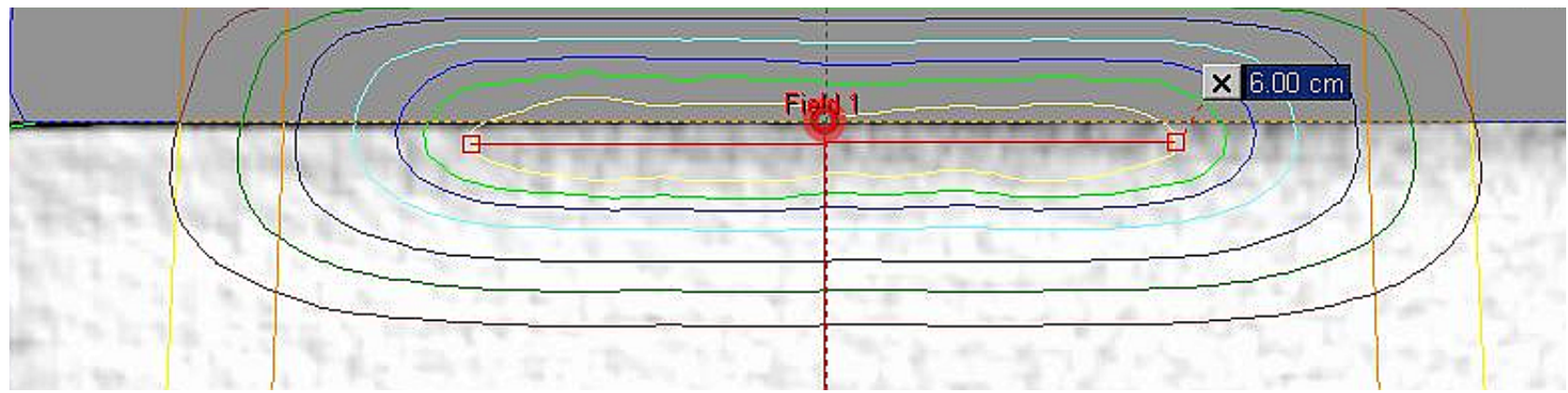

(a)

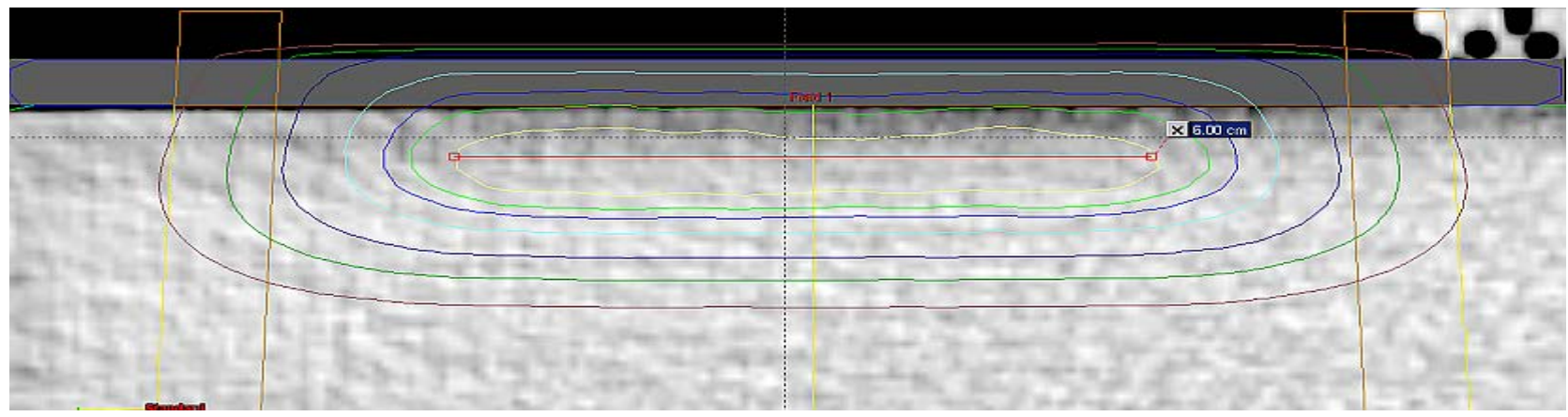

(b)

Figure 4. The dose distribution for $6 \mathrm{MeV}$ electron field, (a) with $1 \mathrm{~cm}$ tissue-like bolus, (b) with $0.5 \mathrm{~cm}$ bolus. $8 \times 8 \mathrm{~cm}$ field determines $6 \times 6$ therapeutic area. 
Conformal treatment plannings have been performed for a female patient irradiated on the rib cage area in order to account patient's anatomic conditions such as: critical tissues presence and uneven surface features. The target included the recurrence area of breast cancer in the post-operative scare, thus in the skin and subcutaneous tissue.

The target as well as the critical organ-lung-have been determined on the basis of CT examination in order to protect residual doses beyond the target. The treatment plannings have been performed by means of the following techniques:

1) Electron beam technique which cross section-radiation field, bolus thickness, dose normalization value have been determined on the basis of compliance-conformal planning rules (Figure 5).

2) For contact brachytherapy application, FLAP applicator has been put on the female patient's skin during the CT image data preparation; consequently, after the target has been determined, the optimization of the guide catherers system and stoppage timings of moving source has been performed in such a way that a referential dose includes the defined subcutaneous tissues layer (Figure 6).

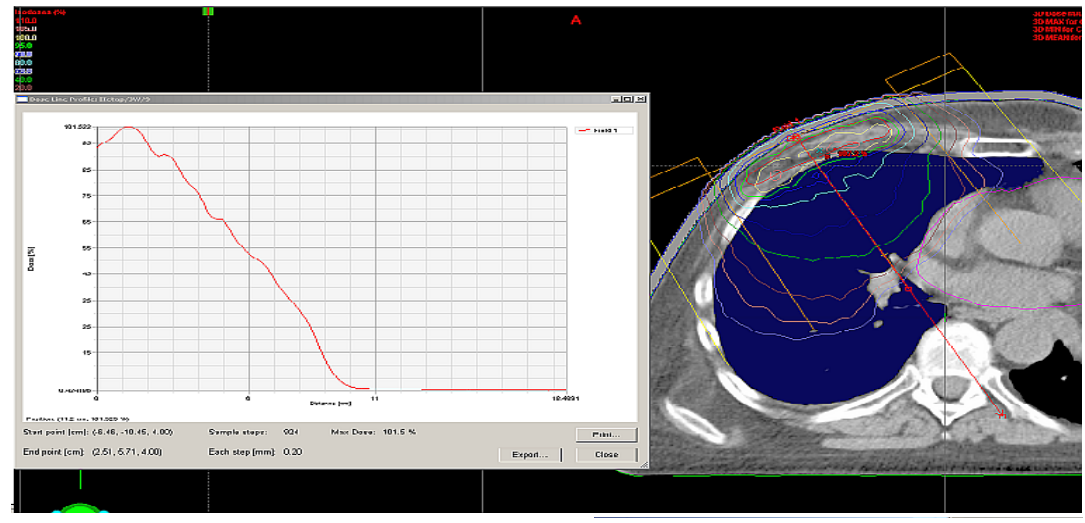

(a)

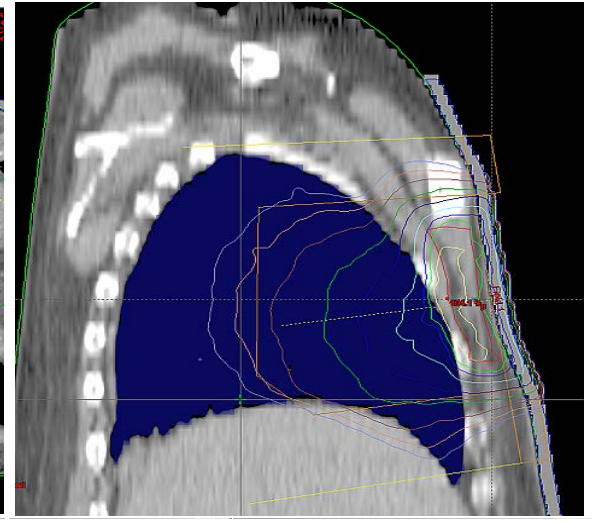

(b)

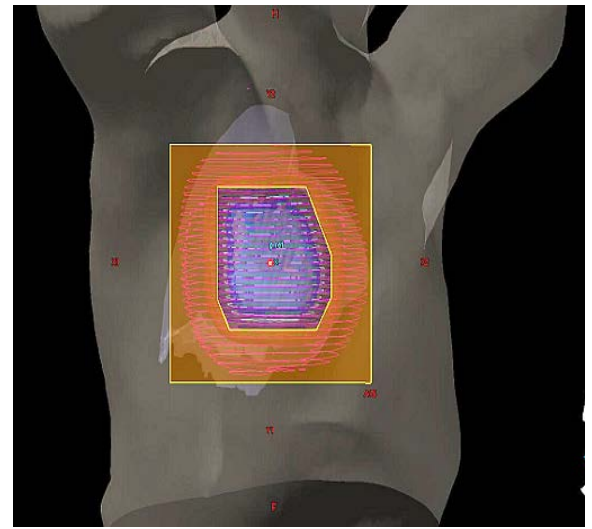

(c)

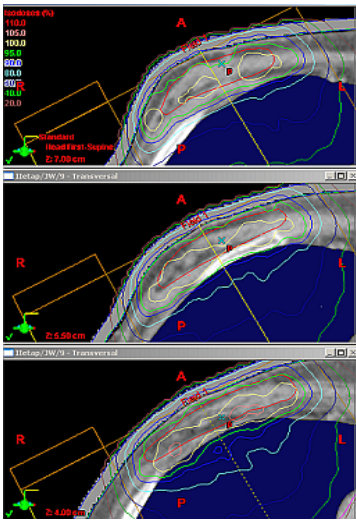

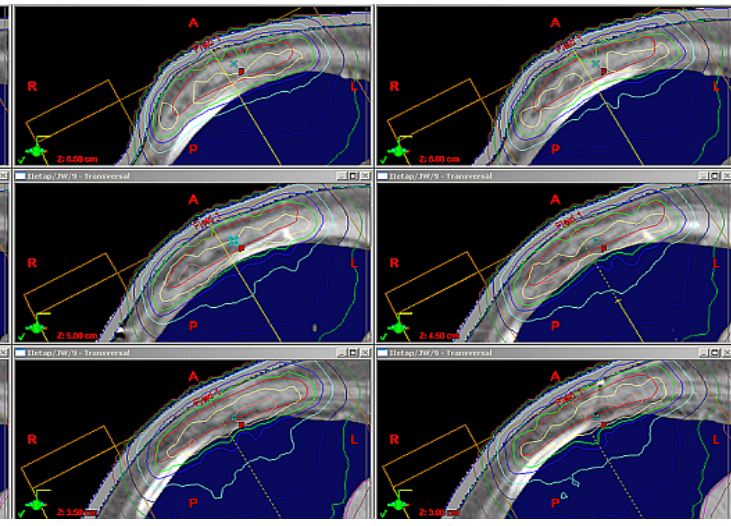

(d)

Figure 5. Electron beam treatment planning $9 \mathrm{MeV}$ electrons, bolus $0.5 \mathrm{~cm}$. (a) dose drop-off in the axis of the beam with crosswise division, (b) dose distribution in sagittal reconstruction, (c) shape of the radiation area, (d) doses distribution in several cross sections. 


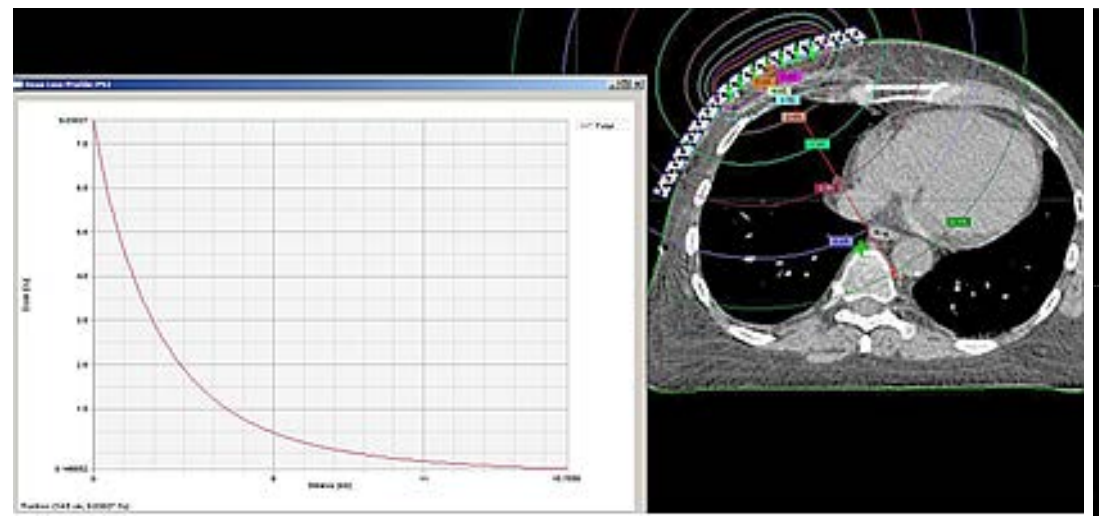

(a)

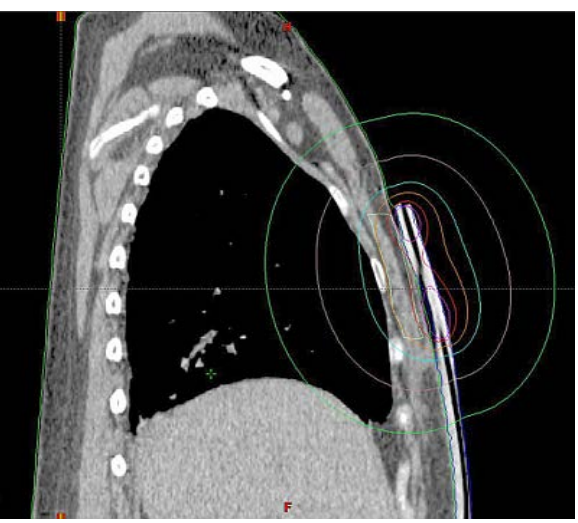

(b)

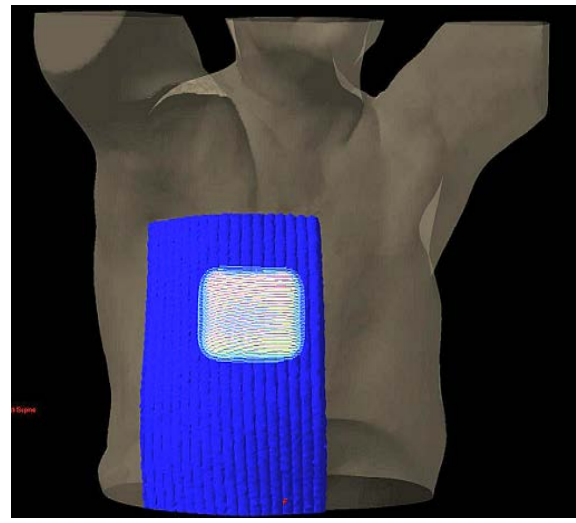

(c)

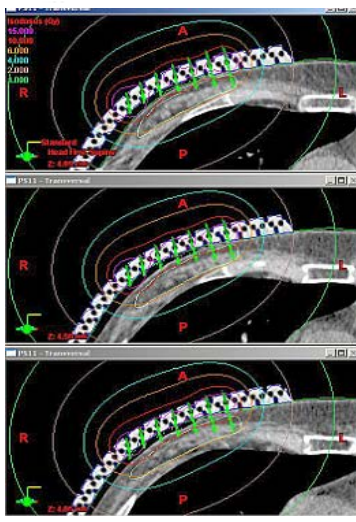

Figure 6. Dose distribution in brachytherapy technique with FLAP applicator. (a) dose drop-off in perpendicular line towards the applicator surface with cross section, (b) dose distribution in sagittal reconstruction, (c) applicator localisation on a 3D reconstruction, (d) doses distributions in several cross sections

3) IMRT of four $6 \mathrm{MeV}$ photon beams dynamically formed on the basis of reverse planning rules. Two IMRT treatment plannings have been performed (Figure 7). The first one, in which the dose optimally covers the target, but the lung is burden with higher residual doses and the second one, where the dose has been decreased in the lung area, but at cost of the covering the tissues attached to target with referential dose.

A computational algorithm of Eclipse system includes the correction of decreased lung tissue density for electron beams and photon beams formed dynamically in IMRT. Unfortunately, Brachy Vision computational module, similarly to most of the computational systems used in brachytherapy does not include in its calculations the heterogeneity tissue correction. In order to perform a qualitative comparison of doses distribution in the above mentioned techniques, the isodoses distributions in cross sections and in sagittal sections have been presented. In relation to different ways of dose fractionation in outer beams techniques and in brachytherapy, a nominal dose distribution in percent has been compared.

Contemporary treatment planning systems give opportunities to sum up the physical doses distributions originated from different stages and different 


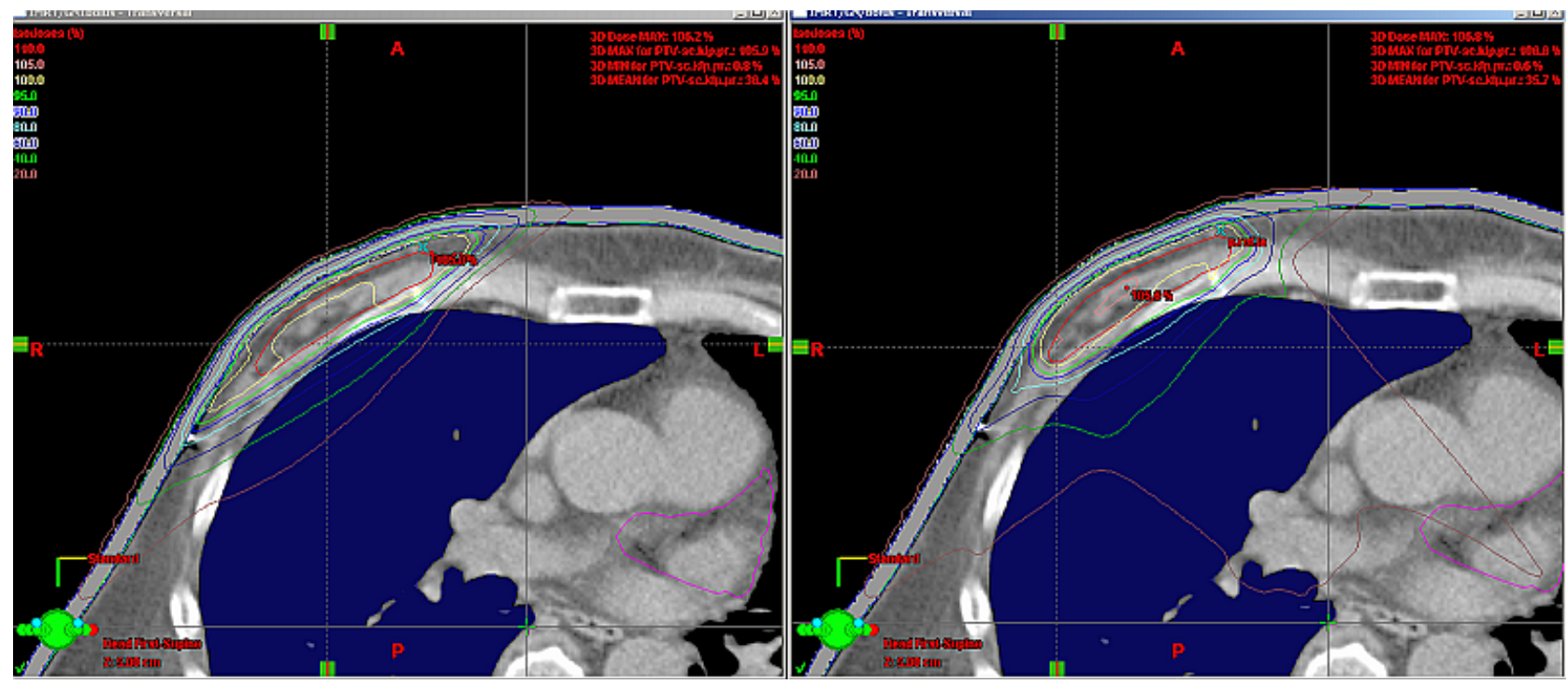

(a)

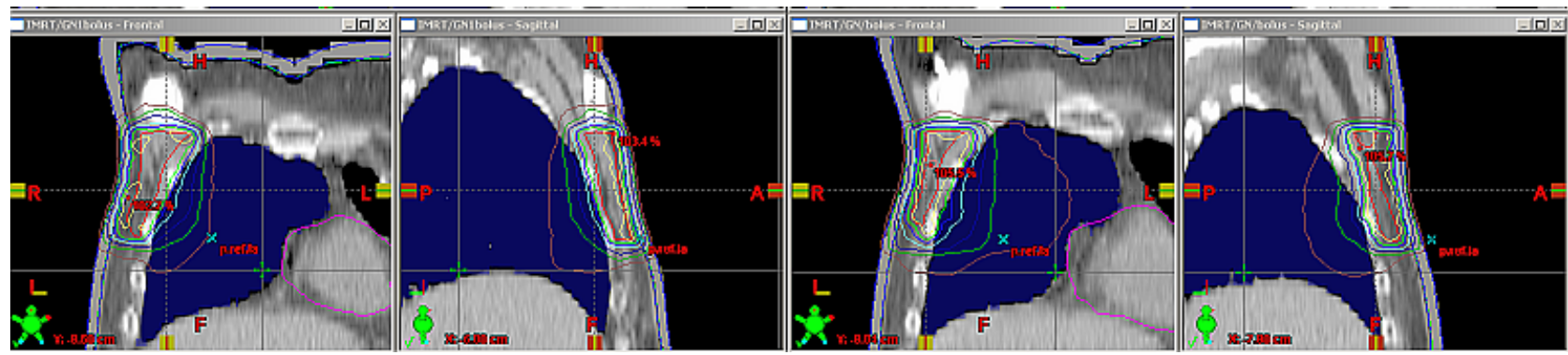

(b)

Figure 7. An example of dose distribution in IMRT technique with the use of $6 \mathrm{MeV}$ photons. 2 methods of optimisation (a) with lung saving, (b) with optimal adjustment of dose distribution to target at cost of higher dose in the lung.

technologies of conformal treatment plannings. Brachy Visio system integrated with the calculation system Eclipse gives the opportunity to perform a summing up treatment planning: teleradiotherapy and brachytherapy (Figure 8). Let us now consider the following case:

1) 1st stage of the treatment-conformal planning for outer beams on the rib cage area after mastectomy $45 \mathrm{~Gy}$ in 20 fractions.

2) 2nd stage-additional radiation of skin layers within the non-radicalness of the treatment or potential recurrence within the scar area. The 2nd stage has been planned within contact brachytherapy technology and, alternatively, by means of electron beam. Isodose divisions of summary treatments plannings have been performed as well as the histogramic division for the lung area and a target of recurrence in the scar. The summed up dose distributions have been expressed in Gy, assuming that the dose of the $2^{\text {nd }}$ stage was $6 \mathrm{~Gy}$.

Histogram dose-volume is one of the supporting tools in the treatment planning assessment. The statistical attempt analyzed in histogram is the dose in voxel CT. Graphs shown on Figure 9(c), d present the cumulative histograms of summary treatment plannings for the lung area Figure 9 (c) and for the target area Figure 9(d). The blue line shows the dose distribution for technique $1^{\text {st }}$ 


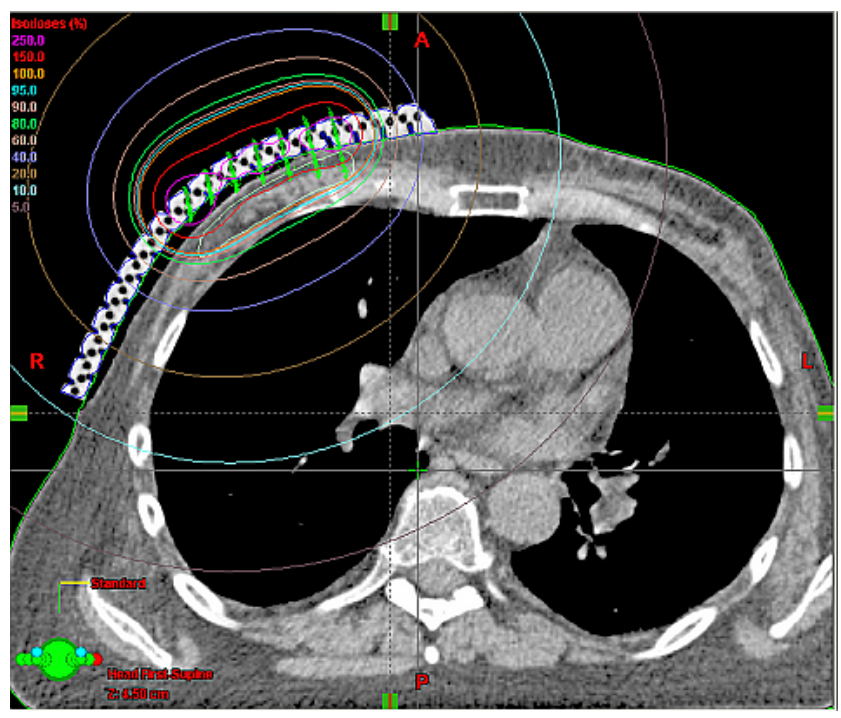

(a)

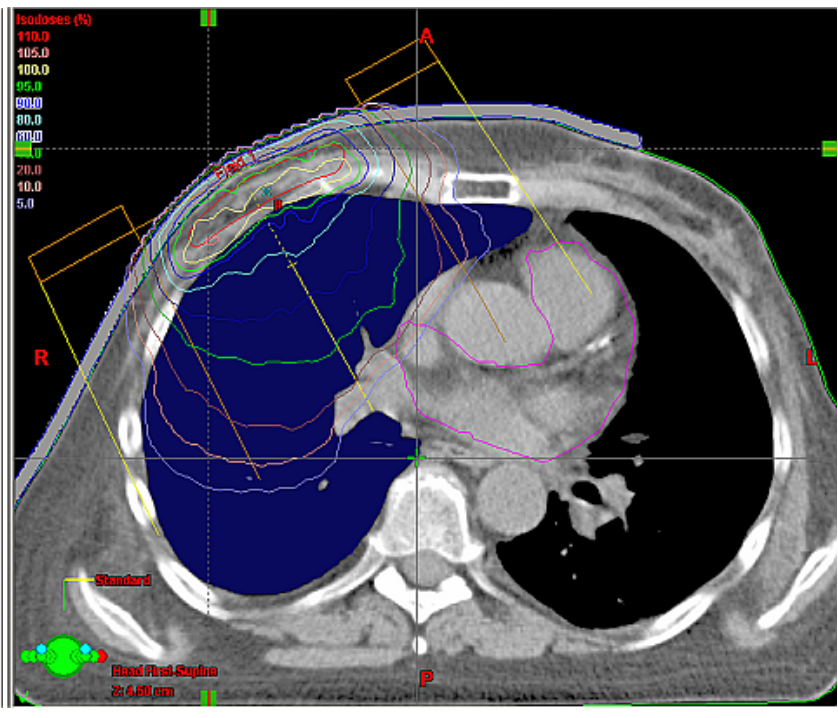

(b)

Figure 8. Qualitative comparison of 2 treatment techniques-(a) brachytherapy and (b) electron beam $9 \mathrm{MeV}$, bolus $0.5 \mathrm{~cm}$.

stage $+2^{\text {nd }}$ stage realized by electron beam, red line $1^{\text {st }}$ stage $+2^{\text {nd }}$ stage realized by contact brachytherapy technique. The decreased dose cumulated in the lung area and more homogeneous dose within the target area during the radiation with electron beam in the $2^{\text {nd }}$ stage of treatment is a result of short-term dose distribution of corpuscular electron radiation.

\section{Discussion}

The discovery of ionizing radiation 100 years ago from both natural sources, such as radium $\mathrm{Ra}^{226}$ and generated as a result of braking electrons sped up by the potentials difference, an X-ray, resulted from the very beginning in its use in skin cancer treatment. Also today the contact brachytherapy methods and X-ray treatment are very important in independent and postoperative radiotherapy [8].

The discovery of artificial radioactivity in 1930s and the advanced automatics and informatization of medical technologies allowed the development of brachytherapy methodologies, that are currently used in after loading techniques [9]. The technology of high-energy linear accelerators that generate a.o. the corpuscular radiation as an electron beam allows delivering of maximum dose shallow under the skin with a small scope of residual radiation at the same time [10].

The radiation therapy with X-rays has actually been completely eliminated from skin cancer and subcutaneous tissue radiotherapy by the electrons generated in linear accelerators, contact brachytherapy HDR and by high-energy photons used in conformal techniques, ex. IMRT [6].

\section{Conclusions}

The reason for the elimination of X-rays as a method of treating skin cancer is due to the fact that the residual dose beyond the target is the highest for single 


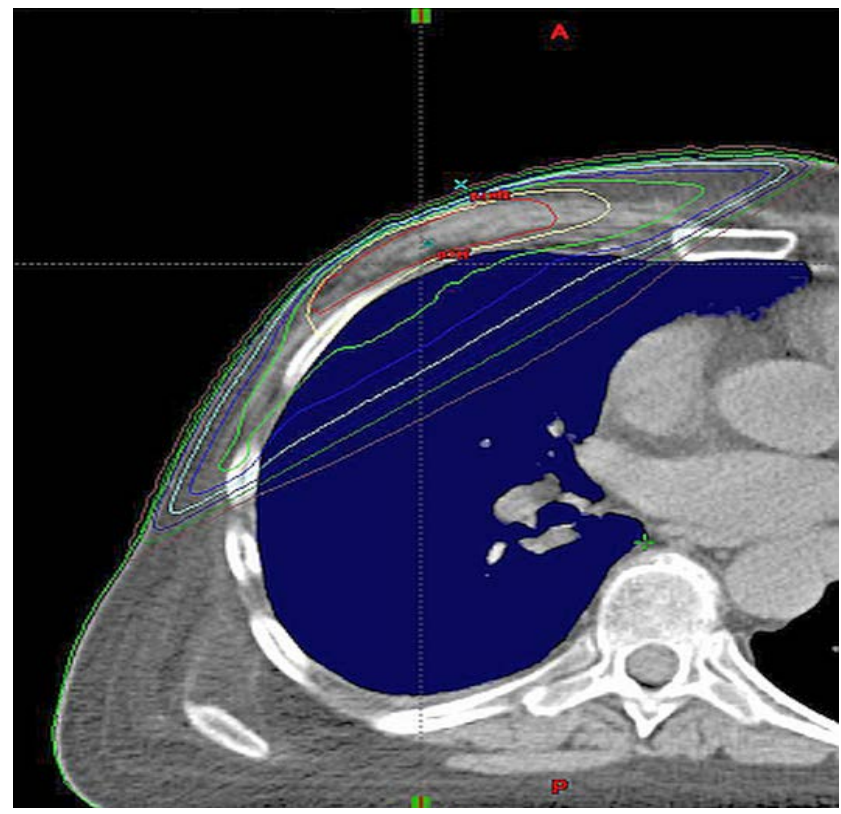

(a)

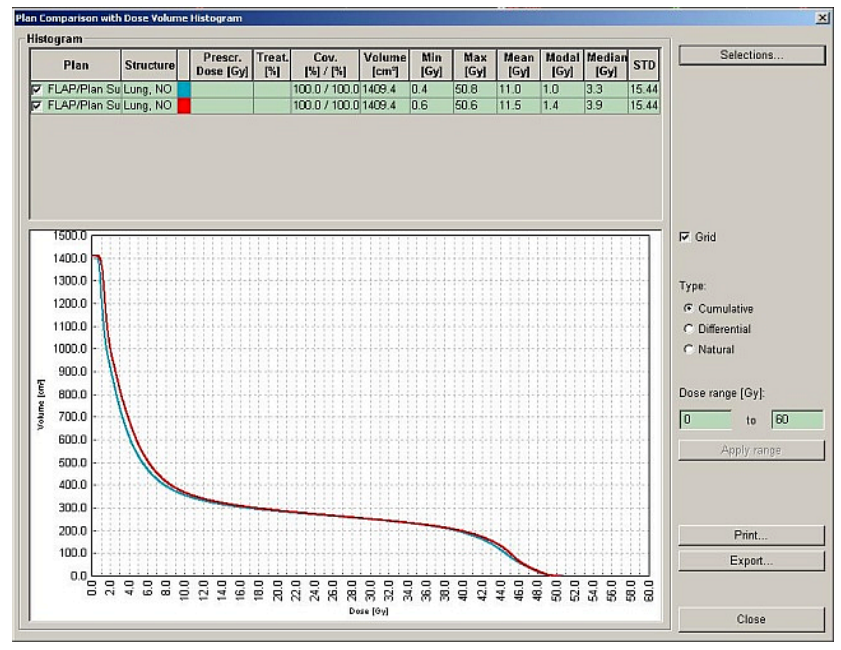

(c)

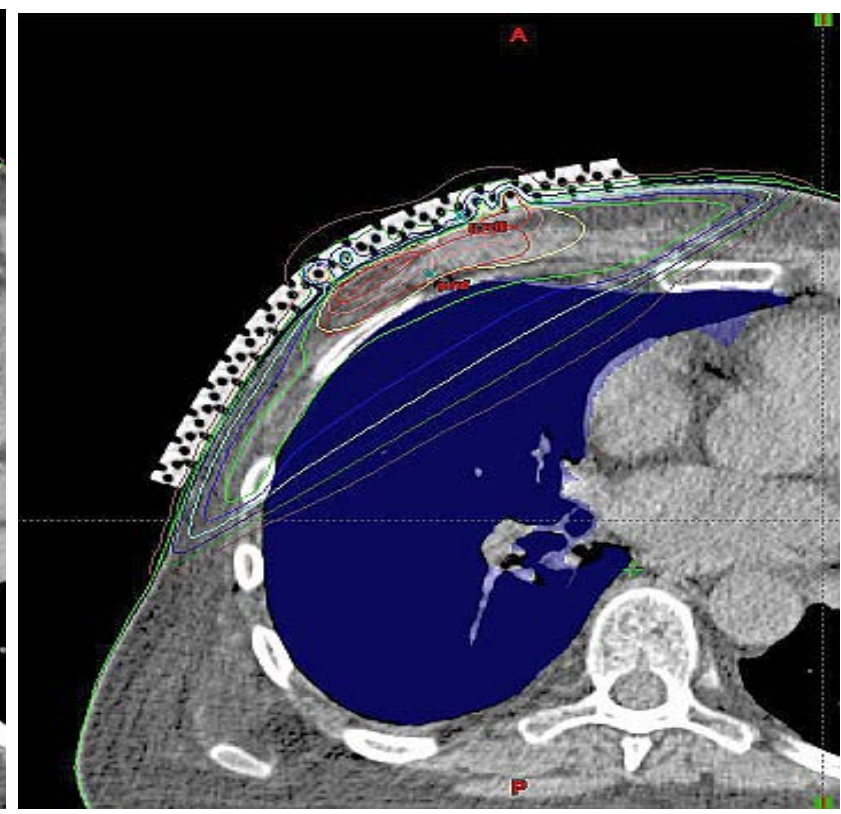

(b)

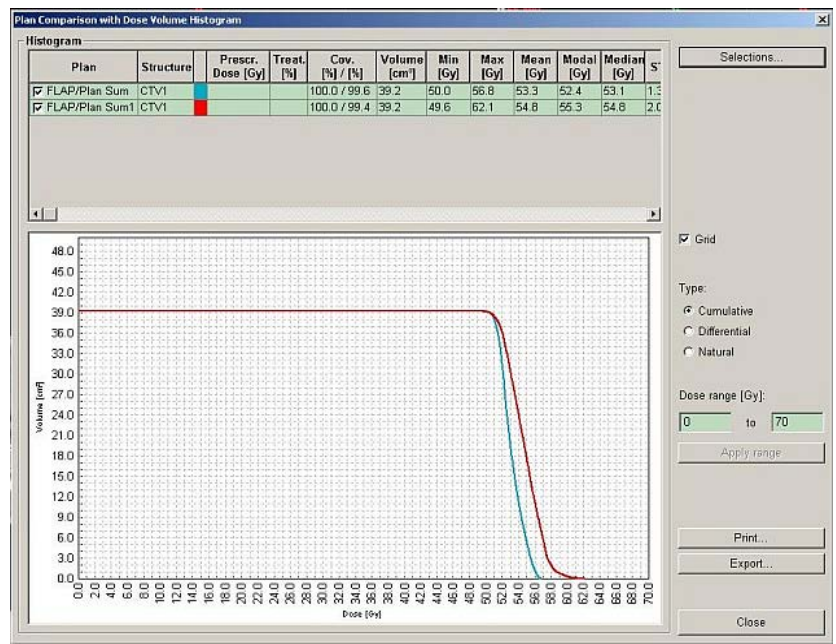

(d)

Figure 9. Summary physical doses distribution for technique with additional radiation with (a) electrons and (b) brachytherapy. (c) The dose distribution in the lung. (d) The dose distribution in the target-red line for brachytherapy, blue line for electron beam.

X-ray beam. Although in brachytherapy HDR a rapid dose drop-off is observed, $5 \mathrm{~cm}$ from its normalization level for the target the residual radiation remains at the level of several percent. So, both X-rays beam radiation and brachytherapy in skin cancer treatment is connected with the administration of the dose with a high gradient in the health tissues. This fact is of a great importance in skin and subcutaneous tissue cancer treatment. If a minor shallow invasive carcinoma is irradiated with gradient techniques then the patient is unnecessary exposed to post-radiation changes with doses absorption in health tissues lying under it. It is important particularly when it comes to high density tissues, ex. bones, where post-radiation effect after X-rays treatment is enhanced by the photoelectric ef- 
fect. In clinical situations on the other hand, where the depth of invasive carcinoma is unknown or unsure or a performer surgery is non-radical, then the use of gradient techniques can be desired because the absorbed dose by the microinvasive cancer cells can be enough to sterilize them and protect the patient from recurrence [11].

The dose distribution for photon conformal techniques IMRT or for electron radiation looks different. There with the dose normalization at the level of $90 \%$ or $85 \%$ we deal with the dose layer, the division does not exceed $15 \%$ of heterogeneity. Additionally, after tissue-like material has been used-bolus-we can receive $100 \%$ of therapeutic dose on the patient's skin. The undoubtful benefit of treatment planning with electron beams is the use of $3 \mathrm{D}$ treatment planning system that works based on the CT depiction. The graphic presentation of isodoses on particular sections, the summing up of doses of different treatment stages, statistic analysis with the use of histogram dose-volume are absolute merits of this technology. The use of his system for doses calculation in case of brachytherapy has its inconvenience, because of the fact that the system does not take into account the heterogeneity of the tissues, but it does take into account the shape of FLAP applicator position and it allows for a quick optimization of referential isodose shape in several plates at the same time. In the areas with no crosswise shapes of patient's body and the flat position of the applicator can be calculated on the cuboidal tissue-like phantom that simulates the patient. Calculations in $2 \mathrm{D}$ system are laborious and they require a precise definition of references location of points that matches all the coordinate stop positions of the iridium source [12].

IMRT technique is undoubtedly one of the most precise methods. It allows for the optimal preparation of dose distribution within the target area, when the dose in critical tissues is as small as possible. Yet, a good treatment planning in radiation therapy is not only the one that is represented by a correct dose distribution, but the one that next to the acceptable dose distribution is easy to be realized and is reconstructed. IMRT technique in the movable area, such as rib cage creates several potential difficulties in optimal radiation therapy realization. Without the stability of patient's arrangement there one cannot talk about correct IMRT radiation therapy and the use of respiratory gating in the case as described above can unnecessary lead to complications of the technique in use while there are other acceptable and less complicated treatment techniques. Conformal radiotherapy is a treatment process that is correct not only because it complies with the dosimetric requirements but it is also an optimal process when it comes to patient's comfort during radiation. Therefore, the single-field techniques or contact brachytherapy which preparation is based on the highest quality of the treatment planning method do comply with these requirements [10] [12].

The use of conformal methods in electron beams technique and brachytherapy HDR outlines a new quality in the usage of these fundamental tools of radiation therapy. 


\section{References}

[1] Perez, C.A. and Brady, L.W. (1997) Principles \& Practice of Radiation Oncology. 3rd Edition, Lippincott Raven, Philadelphia, Chapter 27, 723-744.

[2] Kordek i wsp. (2003) Onkologia: Podręcznik dla studentów i lekarzy. Warszawa, 217-221.

[3] Jabłońska, S. and Chorzelski, T. (2002) Choroby skóry. Rozdz, 21-22, 375-402.

[4] Lawrence, C.M. (1999) Mohs' Micrographic Surgery for Basal Cell Carcinoma. Clinical and Experimental Dermatology, 24, 130-133. https://doi.org/10.1046/j.1365-2230.1999.00433.x

[5] Locke, J., Karimpour, S., Young, G., et al. (2001) Radiotherapy for Epithelial Skin Cancer. International Journal of Radiation Oncology ${ }^{\star}$ Biology ${ }^{\star}$ Physics, 51, 748-755. https://doi.org/10.1016/S0360-3016(01)01656-X

[6] Swanson, N.A. (1983) Mohs Surgery. Technique, Indications, Applications, and the Future. Archives of Dermatology, 119, 761-773. https://doi.org/10.1001/archderm.1983.01650330053014

[7] Skowronek, J., Piotrowski, T. and Zwierzchowski, G. (2001) PDR Brachytherapy-Describing of a Method and a Review of Clinical Applications. Reports of Practical Oncology and Radiotherapy, 4, 197-202. https://doi.org/10.1016/S1507-1367(01)70973-X

[8] Gerbaulet, A., Pötter, R., Mazeron, J.J., Meertens, H. and Van Limbergen, E. (2002) The GEC ESTRO Handbook of Brachytherapy. ESTRO, Mounierlaan 83/12-1200 Brussels, Belgium Brussels, Chapter 1, 28, 3-21, 573-584.

[9] Makarewicz, R. (2004) Brachyterapia HDR. Wydawnictwo Via Medica, Gdańsk.

[10] Lovett, R.D., Perez, C.A., Shapiro, S.J., et al. (1990) External Irradiation of Epithelial Skin Cancer. International Journal of Radiation Oncology ${ }^{\star}$ Biology ${ }^{\star}$ Physics, 19 , 235-242. https://doi.org/10.1016/0360-3016(90)90529-S

[11] DeVita Jr., V.T., Hellman, S. and Rosenberg, S.A. (2001) Cancer: Principles and Practice of Oncology. 6th Edition, Lippincott Williams \& Wilkins, Philadelphia, PA, Chapter 41.

[12] Wilder, R.B., Kittelson, J.M. and Shimm, D.S. (1991) Basal Cell Carcinoma Treated with Radiation Therapy. Cancer, 68, 2134-2137.

https://doi.org/10.1002/1097-0142(19911115)68:10<2134::AID-CNCR2820681008> 3.0.CO;2-M 